\section{Actores y variaciones en las trayectorias de la imagen fotográfica}

María Ximena Betancourt Ruiz ${ }^{(1)}$ y Laura Nathalia Vega Laverde ${ }^{(2)}$

Resumen: La necesidad de reflexionar acerca del papel "educativo" que cumple la fotografía en la domesticación de la población al ser medio y dispositivo que guía lecturas manipuladas de la realidad en pro de los intereses dominantes, es apremiante. El proceso de paz es el detonante del análisis que se presenta en este texto para aportar a la discusión sobre el papel y el sentido que tiene hoy la fotografía. Este tema articula la "realidad" colombiana iniciando el siglo XXI como contexto con la forma en como esta es representada ante los mismos colombianos y ante el mundo a través de las fotografías que circulan en medios. La firma del Acuerdo de Paz a finales de 2016 da inicio a una "nueva época" para algunos "postconflicto", para otros "post-acuerdo". Varios hitos marcan este proceso: largas reuniones, encuentros y enfrentamientos, además de manifestaciones, fueron captados por fotógrafos oficiales y particulares. Su postura, su mirada, al momento de la toma, la edición de la misma, la ideología del medio que la difundió, entre otras cosas, hacen parte de las formas en que la educación como aparato ideológico del estado se expresa por fuera de los muros de las instituciones educativas, valiéndose en la actualidad de las tecnologías que instrumentalizadas, le dan vía libre a la reproducción del poder, resignificando y tergiversando a través de códigos esa "realidad" en la que estamos inscritos.

Palabras clave: Educar la mirada - Imagen fotográfica - Pantallas - Panóptico - Educación y poder - Medios - Representación.

[Resúmenes en inglés y portugués en las páginas 55-56]

(1) María Ximena Betancourt, Diseñadora gráfica de la Universidad Nacional de Colombia. Doctoranda en Estudios Sociales, de la Universidad Externado de Colombia. Docente Asociado II en Universidad de Bogotá Jorge Tadeo Lozano. mariax.betancourtr@utadeo. edu.co; ximenb@hotmail.com

(2) Laura Natalia Vega Laverde, Fotógrafa de la Universidad de Bogotá Jorge Tadeo Lozano. Fotógrafa Profesional Conservacionista Señal Memoria en RTVC, Sistema de Medios Públicos de Colombia. lauran.vegal@utadeo.edu.co ; lauravegaphotography@gmail.com ; https://lauravegal.wixsite.com/vegaphotovideoart 


\section{Introducción}

El artículo que se presenta a continuación da cuenta del proceso desarrollado y de los resultados obtenidos en el proyecto de investigación Actores y variaciones en las trayectorias de la imagen fotográfica y de la obra artística que surgió de este-Colección panóptico de la educación para la paz-, ambos desarrollados durante el 2019. Su base, la imagen fotográfica, pues al ser copia, ilusión del mundo, expresión artística, soporte visual de la memoria, poética que recupera instantes, documento social que informa, explica o denuncia; también es medio de reproducción de las ideologías dominantes y cuando lo hace se pone en juego la idea de verdad de su representación, cuestionando sus bases éticas y su función estética. Por lo tanto el proyecto se propuso, a través de un estudio de caso -Proceso de paz y firma del acuerdo en 2016, entre el gobierno colombiano y las Fuerzas Armadas Revolucionarias de Colombia, FARC-, demostrar el papel "educativo" que cumple la fotografía en la domesticación de la población, específicamente en la búsqueda de una alineación de esta a unos intereses particulares del estado o de grupos que bajo una inclinación ideológica o económica, ocupan un lugar privilegiado en el escenario social.

La metodología cualitativa de carácter interpretativo con base en la semiótica peirceana contribuyó al análisis y a la detección de la eficacia simbólica con la que la fotografía media entre la "realidad" y su representación en el contexto social colombiano fijando aprendizajes/sujeciones deseados en la población.

Los resultados obtenidos dejaron ver la versatilidad, dinamismo y potencia de la imagen fotográfica, invitan a la reflexión y abren caminos de profundización.

\section{Colombia y el proceso de paz}

Más de 50 años de conflicto armado en Colombia lo catalogan como uno de los países con conflicto interno más largo en el mundo. Según datos del 2013 del Centro Nacional de Memoria Histórica, este dejó "unas cifras que hablan por sí mismas: 60.000 desaparecidos, 30.000 secuestros, 13.000 víctimas de violencia sexual, 220.000 muertes”. En el 2016 el gobierno en cabeza de Juan Manuel Santos (2010-2018) firmó un acuerdo de paz con el grupo armado más grande del país, las Fuerzas Armadas Revolucionarias de Colombia, FARC. El proceso de paz que se vivió durante este periodo no fue el primero que se dio en el país. Desde la década de los ochenta se adelantaron diferentes gestiones entre el gobierno y las organizaciones insurgentes. Fueron muchos los años de conversaciones, treguas y acuerdos frustrados por "los incumplimientos a lo pactado entre las partes, la falta de garantías para ejercer la oposición, los ataques a la población civil y el accionar de los grupos paramilitares" (Pares, 2019).

Sin embargo, al ser las FARC la guerrilla más grande del país, en cuanto a su poder económico y militar -ligado al narcotráfico y al secuestro, entre otras actividades-, la culminación del proceso de diálogo entre los diferentes actores fue un paso muy importante para el país, no solo para el logro de la paz sino también porque ante la necesidad de incorporar al país a los planes de desarrollo regional y global era necesario procurar un 
territorio seguro para posibles inversionistas. Cabe recordar que, durante el gobierno de César Gaviria, cuando Juan Manuel Santos fue Ministro de Comercio Exterior, un futuro inversionista le advirtió: "Mientras ustedes tengan esa guerra en su país va a ser muy difícil que atraigan verdadera inversión (...)”. El mismo Santos reitera que ante estas palabras comprendió que además de conveniente, llevar a buen término el proceso de paz era imprescindible (Santos, 2019, p. 63).

Por fin, el 26 de septiembre de 2016 en un acto protocolario y con la presencia de varios presidentes de naciones amigas y veedoras, se firmó en Cartagena el acuerdo final de paz entre el presidente Juan Manuel Santos y el comandante en jefe de las FARC, Rodrigo Londoño alias Timochenko. Documento refrendado por ley en un plebiscito en el que los ciudadanos debían votar «Sí» o «No» al Acuerdo. El resultado final fue una victoria para el «No». Después de una negociación con los promotores del "No", el gobierno y las FARC; el nuevo documento se volvió a firmar el 24 de noviembre del mismo año. Los 6 puntos que se consideraron más importantes en este texto fueron: reforma rural, participación política, fin del conflicto, narcotráfico, víctimas y verificación e implementación.

\section{Los medios de comunicación en el proceso de paz}

La preponderancia que tuvo en esos días el proceso de paz, la firma del acuerdo y el "No" ganador durante el plebiscito, se debió en mucho a lo expuesto por los diferentes medios de comunicación. De esto da cuenta la investigación adelantada por el Observatorio de Medios de la Facultad de Comunicación de la Universidad de la Sabana. Este centro indagó sobre los imaginarios que los colombianos tenían en ese entonces, sobre el proceso de paz relacionados con la información recibida a través de medios de comunicación. En sus conclusiones indica la importancia de la labor pedagógica que cumplen los medios con el fin de propiciar vinculaciones efectivas de la sociedad civil a un hecho o idea y mejorar la opinión pública. $\mathrm{Al}$ respecto en el documento se puede leer:

La labor pedagógica, que debe partir de un auto convencimiento frente al proceso, de ir ambientando el respaldo ciudadano y el optimismo moderado dentro de un contexto en donde los sacrificios van a ser necesarios. Comunicativamente dicha labor puede respaldarse en la muestra de experiencias de procesos de paz en otros países y testimonios de personas protagonistas de negociaciones y diálogos similares.

En el mismo sentido insiste que:

La construcción de actitudes frente al proceso de paz está influenciada por el papel que los medios de comunicación y los actores del proceso puedan tener en la construcción mediática de la realidad política. Las dimensiones reales e imaginarias pueden contraponerse entre unos avances o retrocesos objetivos de la negociación, hechos y acontecimientos coyunturales o colaterales de la 
realidad política relacionados o no con el proceso y el conflicto, y las percepciones subjetivas de la realidad acompañadas de sentimientos "utópicos" o del deber ser que pueden ir acompañados de optimismo o pesimismo, esperanza o decepción, conformismo o inconformismo.

Lo anterior es fácilmente identificable en noticias y artículos que fueron emitidos en diferentes medios durante ese álgido periodo por el que atravesaba Colombia. Pero, qué sucedía con las imágenes, fotografías, ilustraciones, caricaturas. En efecto, no solo ilustraron el proceso, también ejercieron fuertes mediaciones que es necesario revisar, pues hacen parte de las intenciones "pedagógicas" provocadas por los medios sobre las audiencias.

En consecuencia, puede afirmarse que los medios de comunicación ejercen de alguna manera, como un enfoque pedagógico y sus canales y soportes son herramientas didácticas que median y vehiculizan los contenidos transmitidos por la imagen fotográfica, en mucho, gracias a los desarrollos tecnológicos que han abierto inmensas posibilidades de socialización. Los dispositivos con pantalla hacen parte del espacio vital del ser humano, permean todos los espacios de la vida y su inmediatez y fluidez procura credibilidad sobre lo que se emite aunque no tenga mayor profundidad, por ello su uso por parte de grupos de poder es cada vez más común. En efecto los contenidos emitidos por canales institucionales y privados durante este periodo promovieron de forma abierta o tácita la adhesión de los colombianos al proceso de paz y a las acciones desarrolladas por el gobierno y por las Farc para su consecución. Las ubicuas y dinámicas pantallas de todo tipo de dispositivos fueron el soporte que impactó tanto a los ciudadanos del común como a las élites y el espejismo de saberse informado funcionó a la perfección.

\section{Fotografía, educación y medios}

Los años subsiguientes a la firma del acuerdo fueron coyunturales para el país. Se empezaban a ver las consecuencias e impactos de la firma y se proyectaba una urgente necesidad de "modernización" que el gobierno asoció al uso de tecnologías a gran escala para la industria en general y a las tecnologías específicas en el marco de la regulación de la información y de la comunicación TIC. Estas fueron normatizadas por el Estado a través del Ministerio de Tecnologías de la Información y Comunicaciones de Colombia, MINTIC (Mintic, 2019). Una gestión relacionada más con la cobertura y la accesibilidad y menos con la calidad de contenidos o a la educación necesaria para un uso crítico, dan cuenta de esta gestión instrumental de la tecnología.

Formas, tamaños y colores desempeñaron un papel importante en cómo la visualidad permeó nuestro imaginario de la realidad que atravesamos como país en el largo proceso de la firma del acuerdo de paz. En efecto fuimos educados a través de la mirada, la teoría de la Gestalt puede dar fe de ello: un proceso a través del cual los seres humanos a partir de imágenes, sonidos, tacto y memoria construimos marcos de percepción de la realidad, representaciones mentales que vamos creando sin darnos cuenta y sin embargo son la base para interpretar la realidad y tomar decisiones. 
La fotografía ocupa un nivel preponderante ya sea por su capacidad para "representar la realidad" de manera cercana, su valor como documento, la posibilidad que tiene de ser reflejo de la memoria, de proyectar sensibilidades logrando magníficas experiencias sensoriales. Acompaña todas las acciones humanas, documento, referencia, ilustración y siempre comunicación. Pero como imagen es polisémica y por ende, esconde, disimula, vela y fácilmente se convierte en subterfugio del poder.

¿Es necesario retar al fotógrafo para que asuma el desafío de ser crítico y ético con las imágenes que crea, con su uso y proyección? Sí, pues estas educaran quiéralo o no su autor así que es responsabilidad tanto de él como del editor.

Preguntarse cómo educan las imágenes a través de los medios de comunicación, no obliga al fotógrafo a perder su autonomía ni a hacer consciente una postura, un fin, una responsabilidad. Es la posibilidad de dejar de lado la sumisión que nos impulsa a aprobar la carga de dominio homogeneizante que implica no cuestionar el sistema de poder que intenta domesticarnos por medio de repeticiones constantes de discursos visuales emitidos a través de distintos medios de difusión.

Claro está que la posición del fotógrafo no es tan sencilla, enfrentado con la realidad del medio, se ve avocado a la producción de imágenes a pedido, en serie. La luz, el punto de vista, el encuadre, la mirada, antes esenciales en su hacer, ahora son mera producción y reproducción en espacios de difusión controlados que según Imbert y Beneyto (1986), restringen su expresividad y los alcances de su producción, al mismo tiempo que dominan y limitan las formas en que esta es observada por los sujetos a los que va dirigida.

\section{Imagen representación y medios. Subterfugio del poder}

Los análisis de imagen realizados en el marco conflictivo del país, mostraron que la imagen fotográfica funciona como una "forma velada" de ilustrar la realidad. Por ello era urgente cuestionar el papel de la fotografía en la construcción social, en la mirada del mundo en el que vivimos, en el impacto del fotógrafo, su postura y su mirada como creador de imágenes y su papel como crítico del sistema o como reproductor del mismo a través de las imágenes que crea.

Cuestionamientos tendientes a identificar si las imágenes fotográficas del conflicto educan, si lo hacen, ¿cómo activan el aprendizaje y qué enseñan?; si en ellas como ilustradoras del discurso escrito se identifica fácilmente el contexto, los actores y la dimensión política de la situación que representan o se necesita estar altamente calificado para comprenderlas; y finalmente se supuso que la imagen fotográfica gracias a la pantalla que la soporta, que la repite y la multiplica, logra la omnipresencia que la convierte en panóptico de la sociedad actual si no, aparato ideológico del Estado.

Tratar de responder a estos cuestionamientos y corroborar la hipótesis del panóptico, abrió un camino de indagación que incluyó teorías, referentes, noticias y por supuesto la recopilación de más de 5000 imágenes aparecidas en medios antes, durante, y después de la firma del acuerdo de paz. Se buscó identificar en 5 imágenes fotográficas representativas de diferentes momentos del proceso de paz, el papel de la fotografía como dispositivo de 
control del estado a partir de su capacidad de educar a la población para asumir sin cuestionamiento las condiciones del sistema dominante. Con precisión se quería contrastar el valor que se le otorga a la fotografía como mediadora/ilustradora, en contraposición al valor de la mirada del fotógrafo que la produce y a la intención del Estado en la que surge; cuestionar el valor mediatizador que se le otorga a la tecnología y a los medios de comunicación que funcionan como soporte de la imagen fotográfica y por último, brindar una propuesta que respondiera al cómo por medio de la imagen fotográfica es posible posibilitar en los otros un conocimiento reflexivo del contexto.

Su desarrollo implicó reconocer la situación actual del país y en esto la celebración del Bicentenario de la independencia de Colombia en 2019, nos recordó el pacto entre gobernantes y gobernados que inició con la declaración de independencia en 1810 y se formalizó con la campaña libertadora en 1819. Los gobiernos que nos han regido desde ese entonces imparten ideales, ideologías, leyes e imponen modos de hacer y pensar avalados por constituciones, instituciones, políticas, leyes y planes de desarrollo que todos los ciudadanos debemos seguir. Como nunca antes, la imagen técnica ha sido protagónica en este proceso, a tal punto que ha logrado trastocar el mundo de la vida y su relación con la verdad y con el poder. La economía y el soft power también han jugado un papel preponderante, países con grandes recursos naturales pero extremadamente pobres versus grandes potencias que acumulan capital y por ende poder, comprueban un neo colonialismo que explican con claridad teóricos de la ciencias sociales como Anibal Quijano (2000), Enrique Dussel (2011) y Walter Mignolo (2003).

El colonialismo en América Latina es producto de la transformación y la pérdida de identidad de la población que habitaba el continente. En sus inicios fue producto de un sistema social y económico que consistía básicamente en que un estado extranjero dominaba y explotaba el territorio. En la actualidad, seguimos siendo dominados, ya no a través del ejercicio de la guerra, sino de formas mucho más simbólicas y novedosas, en donde por lo general la imagen juega un papel protagónico. Ejemplo de esto son los currículos ocultos en las imágenes de los textos escolares como lo evidencia Zenaida Osorio en su texto "Personas ilustradas: La imagen de las personas en la iconografía escolar colombiana”.

\section{Educar la mirada}

Hablar de "educar la mirada" hoy, no es fácil. ¿Cómo es posible enseñar a mirar en un contexto en el que todos se asumen altamente calificados para ver, aunque las evidencias demuestren lo contrario? (Duseeel, 2005). Gran cantidad de imágenes cinematográficas, televisivas, publicitarias, etc., se nos aparecen incesantemente casi que pornográficamente en redes sociales, aplicaciones, páginas web, etc., las transmiten de forma insistente, adhiriéndose inevitablemente a nuestra carne aumentando las extensiones corporales en las que se han convertido para los seres humanos los dispositivos que las vehiculizan. De esta forma aprovechan el voyeurismo desmedido del momento educándonos y así nuestras acciones, decisiones, sentimientos, pensamientos, parecen desatarse por su influjo. Juegan con la conciencia y neutralizan la reflexión ante la ambigüedad del mundo real/virtual. 
Aportes de varios estudiosos en el marco de la denominada cultura visual y los estudios culturales nos permiten entender la dimensión de las problemáticas del impacto de la imagen, ya sea esta pictográfica, iconográfica, fotográfica o ilustrada, en el contexto político, social, cultural y económico actual.

Muchas veces, aunque el soporte en el que se presenta la avala como documento, el papel que realmente cumple es ideológico o publicitario. Es una forma de distraer y confundir al espectador con lo que se cumple su función de subterfugio. Didí-Huberman (2017) en su reflexión dice "lo que vemos no vale -no vive- más que por lo que nos mira". Y en esto hay tensión, estar en sublime contemplación, estar presos eternamente de la mirada, o estar en observación crítica que procure la preservación de la dignidad y la libertad, camino que invita a ahondar en una "otra" pedagogía de la imagen.

La tradicional pedagogía de la imagen sucumbe a la técnica. Luz, color, planos, etc. se minimizan describiéndolos. Para evitar reincidir en las descripciones básicas se consideró una carta de navegación con base en las siguientes categorías teóricas:

Educación para la libertad, a partir de los postulados de Paulo Freire, quien insiste en la educación como uno de los pilares para construir una sociedad más justa que permita a las personas desarrollarse como individuos más que como sujetos, tomando conciencia de quienes son y el lugar que habitan. Esta premisa que propende por la libertad no ha producido el fruto de la transformación social deseada, por lo general se ha tergiversado a través de prácticas de control que se han normalizado viéndose como justas. Paulo Freire identifica un modelo de sociedad sin identidad que persigue un ideal eurocéntrico de la educación que no permite un poder participativo de la comunidad a partir de contraponer la educación como práctica de la libertad con la "educación para la domesticación". En otras palabras, una sociedad que copia con constancia los modelos eurocéntricos con los que pretende educar a su población desconociendo los desarrollos locales y sus necesidades particulares.

En desmejora de la situación, en la actualidad, educar ya no es hacer pensar, es informar. El modelo de educación bancaria lo explica, una cuenta en donde solo se consigna conocimiento y no hay diálogo entre el educador y el educando, es monologal, solo va en una dirección y no permite el poder de la participación. Aparentemente alfabetizar era sinónimo de concienciar, pero según Freire esto no era sino una máscara para los opresores y una trampa para los oprimidos. La educación ve al hombre como objeto para la domesticación y no al hombre como sujeto para la libertad. Al alfabetizar a la población de esta forma, se produce resistencia contra las élites dominantes, crisis de la que emerge la clase popular. "La educación verdadera es praxis, reflexión y acción del hombre sobre el mundo para transformarlo" (Freire, 1982). La praxis como un concepto en oposición a la teoría, modifica a la educación convirtiendo la experiencia vivida como parte del aprendizaje, así como la reflexión sobre el conocimiento adquirido y no únicamente como un cúmulo de datos que se reciben y quedan guardados sin sentido alguno.

El poder participativo. Enrique Dussel, filósofo y profesor, en una entrevista sobre " $\mathrm{La}$ Ruta pedagógica, decolonialidad del poder", habla sobre la necesidad de transformar el Estado y cómo las instituciones son importantes para la sociedad y la justicia. El concepto de 
transmodernidad es planteado por el mismo autor, como una nueva edad del mundo y no como la posmodernidad, como la edad que precede a la modernidad que es más eurocéntrica. "Eso significa que no es la última etapa de la modernidad, ni pensamos que va a haber una nueva modernidad, sino que va a haber una nueva edad del mundo" (Dussel, 2016). Sugiere entonces que la modernidad va a quedar atrás y se le llamará transmodernidad, siendo más radical que el pensamiento eurocéntrico posmoderno. Esta nueva edad del mundo, debería permitir que el nuevo estado posibilite a la población un poder participativo que gobierne por medio del consenso y así construir una hegemonía que apruebe un proyecto en común y se disponga el diálogo entre la población.

Freire y Dussel ofrecen un punto de partida para comprender el estado actual de nuestra sociedad y de dónde venimos y posiblemente hacia dónde vamos como habitantes latinoamericanos. Aplicado a Colombia, con una población en su mayoría carente de identidad propia -no porque no la tengan, sino por una capacidad de olvido mediada por la atomización continua del Estado que a través de todas sus instituciones pretende hacer vivir a la población según modelos exportados- recreando una cosmovisión obsoleta que considera tradiciones no europeas ni norteamericanas como carentes, incompletas, no desarrolladas.

Así que el acto de educar se convierte en un problema poscolonial. Inés Dussel (2012), en "Educar la mirada, políticas y pedagogías de la imagen", da cuenta de cómo ya no son únicamente los textos escolares o esta institución las que referencian a la imagen fotográfica como "recurso didáctico" sino como "recurso pedagógico". Las imágenes en todos los medios y soportes, enseñan. Entre muchos saberes, enseñan el rol de la mujer y del hombre en la sociedad, su jerarquización y los papeles que les será posible ejercer a futuro, al mismo tiempo que potencia la discriminación al negar la diversidad.

\section{El proceso de Paz en Colombia y la firma del acuerdo}

Hacia el año de 1964 a raíz de una insurrección campesina y una resistencia agraria contra la violencia latifundista, imperial y militar del momento, bajo el liderazgo de Manuel Marulanda, nacen las Fuerzas Armadas Revolucionarias de Colombia, FARC. Cimentadas en un contexto de prolongadas y complejas luchas de los campesinos por el derecho a la tierra, a la justicia social y a la libertad. Múltiples secuestros, ataques violentos, muertes a civiles y el uso de cultivos ilícitos para la auto financiación, fueron desdibujando la razón por la cual este grupo armado fue constituido.

Aspectos cronológicos desde la creación de este grupo armado hasta la actualidad: la muerte del comandante Simón Trinidad en 2004, el abatido Raúl Reyes en 2008, el fallecido Alfonso Cano por causas naturales en 2008, el abatido Jorge Briceño en 2010 y finalmente sustituido por Rodrigo Londoño (Timoleón Jiménez), quien asumió las negociaciones secretas que Santos había avanzado con Cano; brindan un punto de partida para el inicio del diálogo de paz en La Habana, Cuba en 2012 con el entonces Presidente Juan Manuel Santos. 
En consecuencia el gobierno conforma un grupo negociador liderado por el abogado y diplomático Humberto de La Calle Lombana. El grupo por parte de las FARC estuvo liderado por el abogado y guerrillero Luciano Marín (Iván Márquez). Cuba y Noruega por su parte actuaron durante el proceso como países garantes. El Gobierno de Raúl Castro, brindó seguridad, alojamiento, transporte, salud para las delegaciones y medió para resolver las tensiones entre ambas partes en los momentos críticos de la negociación. Noruega, con una amplia tradición en temas de resolución de conflictos y varios de sus políticos y diplomáticos con gran conocimiento en el caso colombiano, financió la logística en los primeros acercamientos.

Ambas partes conformaron un acuerdo firmado en un acto protocolario el 26 de septiembre de 2016 en Cartagena. A raíz de la decisión de los colombianos del "No" en el plebiscito del 2 de octubre de 2016 para su refrendación, este fue revisado y convalidado por el Congreso, y vuelto a firmar el 24 de noviembre de 2016 en el Teatro Colón de Bogotá.

Este proceso hoy debilitado gracias a las muchas irregularidades surgidas en los documentos normativos en los que se sostiene y al manejo que se le ha dado por parte del gobierno en curso del Presidente Iván Duque, elegido por la mayoría de votantes colombianos en 2018 es altamente controversial en la historia reciente de nuestro país.

Dos momentos claves para entender lo que ha sucedido son, el conocido caso de Seuxis Hernández (Jesús Santrich), detenido en el 2018 por una orden de captura emitida por la Interpol después de ser acusado por narcotráfico, lo que obviamente ocasionó un incumplimiento de los acuerdos pactados y, el anuncio del 29 de agosto de 2019 en el que Iván Márquez, a través de un vídeo informa el inicio de una nueva etapa de lucha de un grupo de disidentes de las FARC.

\section{Visualidad y control}

La historia de Colombia nos ha mostrado cómo desde la colonia, grandes instituciones del poder en cabeza de un Estado nos someten buscando la homogeneización sin tener en cuenta la diversidad de culturas, geografías y sujetos, que hacen parte de este país. En este ejercicio de dominación, la educación ha jugado un papel muy importante. Nuestra formación básica primaria y secundaria inicia con una "educación elemental de la mirada" moldeadora de modos de reflexionar y comprender el mundo que retoman luego las demás instituciones de poder como el Estado, la religión, la familia y los medios de comunicación que coadyuvan a la construcción y dominación de nuestro pensamiento. Cada uno de ellos pone su parte en la transmisión del conocimiento desde la infancia hasta la edad adulta. Aprendemos de nuestra madre la lengua materna y asimilamos el contexto social en el que estamos sumergidos, limitamos nuestra existencia a partir de unas normas colectivas, naturalizamos la pobreza, la violencia, la desigualdad, la corrupción y la injusticia, a través de los medios y las tecnologías que los soportan y; nos apropiamos de un sin número de creencias que a la vez que nos vinculan socialmente, también nos manipulan y nos someten.

A principios del siglo XIX con el descubrimiento de la primera imagen fotográfica, inició una nueva era de la imagen que acogida entre diferentes disciplinas originó el oficio del 
fotógrafo. Han sido importantes los diferentes avances científicos y tecnológicos alrededor de la fotografía, pero también han sido significativos los usos que ha tenido. Empezando con un proceso químico-óptico restringido a expertos hasta su popularización, al poner el oficio en manos de cualquiera que porte un móvil.

Entre los primeros usos que se le dieron a la imagen fotográfica, estaban el campo del documental y del periodismo por requerir un alto nivel de verdad. No obstante, la fotografía no garantiza una fiel representación de la verdad, es apenas un punto de vista, un leve reflejo de la realidad. Pero los medios nos han convencido de su veracidad. Radio, televisión, prensa análogos y ahora digitales, han ejercido su efectiva mediación discursiva. Resulta paradójico que en pleno siglo XXI, todavía pretendamos creer en su veracidad, cuando la información se produce a conveniencia de quien posee la tecnología y ostenta el poder.

Avances tecnológicos, inteligencia artificial y nanotecnología, un mundo manipulado y gobernado por las máquinas, mientras observamos, la inteligencia artificial percibe nuestro entorno de usuario y como consecuencia nos llenan de anuncios que interpretan deseos y nos sumergen cada vez más en el capitalismo. Maravilloso ejemplo el que nos ofrece la serie Black Mirror, cada capítulo nos enfrenta con las situaciones extremas causadas por el uso de la tecnología. Una mirada al futuro, un suceso continuo de manipulación y censura por parte de quienes quieren regular lo que vemos y quienes somos. Convivimos con la censura y la manipulación y el fotógrafo no es ajeno a esta situación, la reproduce, inmerso en esta realidad, está viciado igual que todos los demás (Cigüela Sola \& Martínez Lucena, 2014; Ribeiro, 1999).

Joan Fontcuberta, teórico de la imagen fotográfica, se pregunta por las imágenes censuradas, las invisibles:

Pero que hoy sobren imágenes y corramos el riesgo de ahogarnos en ellas no debe soslayar el problema inverso. La saturación visual nos obliga también, y sobre todo, a reflexionar sobre las imágenes que faltan: las imágenes que nunca han existido, las que han existido pero ya no están disponibles, las que se han enfrentado a obstáculos insalvables para existir, las que nuestra memoria colectiva no ha conservado, las que han sido prohibidas o censuradas... (Fontcuberta, 2016, p. 26).

La saturación visual insensibiliza y endurece al espectador y la superficialidad predomina. Naturalizamos la aparición y desaparición instantánea de las imágenes fotográficas. Imágenes que se consumen y son desechadas rápidamente, vacías e insustanciales. Sin tiempo ni espacio, mínimamente revividas por la experiencia del sujeto. Son la evidencia de la mirada inocente en esta cultura visual de la que hacemos parte ya denunciada por los estudios visuales.

De manera que, la construcción visual de lo social en contraste con la construcción social de lo visual, expone un mundo social plagado de imágenes y una sociedad ciega a cualquier tipo de representación visual, entonces al prescindir de las imágenes como medio o instrumento de investigación se incapacita a las imágenes para construir conocimiento. Esta dualidad que encarna lo visual pone en evidencia cómo en algunos de los campos 
de conocimiento, por ejemplo la sociología, no se valida a las imágenes como medio de representación,

Por cuanto la propia investigación ensayística en el campo de la visualidad cultural toma conciencia de que su actuación participa activamente en el juego de fuerzas -la batalla de los imaginarios culturales- en que interviene. Es un arma efectiva en ese escenario y ha de hacerse críticamente autoconsciente por tanto de que sus propias intervenciones se constituyen como políticamente activas en las evoluciones, transformaciones históricas y desarrollos del registro de la visualidad y los imaginarios circulantes (Brea, 2005).

Por ello la imagen fotográfica es un todo en la cultura visual. Los imaginarios colectivos producidos por esta dan forma a la visualidad, así como la cultura moldea nuestros modos de actuar. Percibimos con todos los sentidos, pero la importancia que se le ha dado a lo visual en la actualidad, suprime a los demás y se centra únicamente en el estímulo visual. Así mismo este opera ciegamente en nuestra idea de la verdad y en una aparente inocencia de la mirada. El ocular centrismo en el que estamos sumergidos, invalida nuestros sentidos, por lo que es importante desafiar la hegemonía y el dominio que tiene el sentido de la visión (Virilio, 1998), y cuestionar de alguna manera que no solo está definida por el medio, sino que también es fruto del llamado acontecimiento visual al convertir a las imágenes a razón de la experiencia, al generar una interacción entre el espectador y lo que observa. Michael de Certeau citado por Pallasmaa (2006, p. 22), advierte de la expansión negativa del mundo ocular:

De la televisión a los periódicos, de la publicidad a todo tipo de epifanías mercantiles, nuestra sociedad se caracteriza por un crecimiento canceroso de la vista, midiéndolo todo por su capacidad de mostrar ó de ser mostrado y trasmutando la comunicación en un viaje visual.

En general, son las imágenes con menor contenido visual o las más replicadas las que generan un mayor impacto y por tanto una notable recordación a futuro. Estas fotografías que predominan en los medios virtuales, son las que están construyendo el pensamiento de la actualidad.

El oficio del fotógrafo, está ligado a los medios de comunicación y a las pantallas que hacen circular sus imágenes y que muchas veces suprime su capacidad de re-presentar al re-editar y elegir de acuerdo a lo que se quiere mostrar. Vemos entonces que así como con el campo escópico de la mirada, entre el espectador y la fotografía hay algo que complementa a esta acción y es el fotógrafo y el medio que se interpone y dictamina lo que finalmente el espectador ve y así mismo es reflejado.

La habilidad para la producción de imágenes fotográficas por las facilidades tecnológicas -cámaras fotográficas en todos nuestros dispositivos, programas de retoque de libre uso, bancos de imágenes, entre otros- repiten y reiteran lo que los entes de poder necesitan que aprendamos. 
En esta compleja hiperrealidad de la simulación virtual, la imagen fotográfica se nutre de representaciones a través de dispositivos móviles multimedia, cámaras compactas, profesionales, satélites de observación espacial de alta resolución. El control de la sociedad se ve afectado por el efecto panóptico y retórico de la imagen que explora la expansión de la mirada en la cultura digital (Pérez, 2011, p. 29).

No pasa con todos ni todo el tiempo, pero sí se podría hablar de una generalidad como bien lo dice Andrés Pérez (2000), las instituciones de poder nos controlan sin que seamos capaces de advertirlo. Recordemos la teoría del panóptico estudiada por Foucault (2000), una forma de estructura arquitectónica carcelaria diseñada por Jeremy Bentham hacia fines del siglo XVIII, aplicada luego en espacios laborales como las fábricas, en los hospitales mentales y posteriormente en espacios educativos.

El poder en una incesante búsqueda por el control, transformó esas estructuras arquitectónicas en un dispositivo móvil fácil de llevar en nuestros bolsillos y aceptado dócilmente (Agamben, 1996), la pantalla. “(...) es un todo que fluctúa como la luz de la imagen; es un acontecimiento. La pantalla acontece, hace su función de manera temporal y su tecnología la hace un dispositivo activable" (Rincón, 2001). Mecanismo de dominio desde el cual somos constantemente observados y examinados, efectivamente el panóptico de la sociedad actual.

\section{Metodología}

La metodología cualitativa de carácter interpretativo con base en la semiótica peirceana contribuyó al análisis y a la detección de la eficacia simbólica de aspectos pedagógicos de la fotografía como mediación entre la realidad y su representación en el marco social. En general con esta metodología se buscó indagar, profundizar y evaluar la mediación de la imagen fotográfica e identificar la forma en cómo está opera, para agenciar, el aprendizaje/ sujeción deseado (Rossi, 2018).

Para conseguirlo se revisaron medios oficiales y no oficiales de carácter digital que emitieron noticias alrededor de ese suceso entre 2012 y 2019 . Entre más de 500 fotografías identificadas, se preseleccionaron 50. Sobre estas se realizó un reconocimiento del contexto ideológico, político y social desde el cual se presentaron lo que acotó el campo para una selección definitiva de 5 imágenes que respondieran a las categorías teóricas abordadas base para el análisis. La identificación se realizó a partir de 5 criterios:

1. Fotografías de medios de comunicación digital de mayor acogida en Colombia, de diferentes ideologías políticas y de carácter oficial y privado. Se utilizaron, un ranking especializado (Najafi et al., 2017 - Amazon.com) sobre medios digitales que poseen mayor audiencia en Colombia, así como sus dueños y su postura política en medios de carácter oficial y generadores de noticias independientes. 2. Fotografías de menor influencia en los medios de comunicación con ayuda de las mismas bases utilizadas anteriormente. 3. Temática y uso de la fotografía en las publicaciones, fotografías con implicación ideológica, 
política o pedagógica o netamente ilustrativa o referencial. 4. Tipo de pie de foto, título, subtítulos y texto que acompaña la fotografía o etiquetas para divulgación de la información. 5. Riqueza semántica / polisemia a partir de una valoración subjetiva.

Las imágenes escogidas fueron ordenadas en una matriz de análisis con base en la diseñada para el proyecto "De la identidad social a la representación visual" (Betancourt, 2014). Entre las 50 preseleccionadas se volvieron a seleccionar 5 como piloto para el análisis propuesto. Se inició el estudio y se encontró la necesidad de sumar aspectos formales y conceptuales específicos: contexto, interpretación visual, técnica, composición, nivel narrativo, nivel semiótico, educabilidad de la imagen, tipo de exposición pública, efecto panóptico de la imagen, imaginarios en imagen, hasta concluir en la interpretación final. Para la interpretación se propusieron las siguientes fases: Descriptiva. Dedicada a la identificación de los elementos básicos y técnicos; Objetiva. Dedicada a registrar el contexto (personajes, objetos, lugar); Analítica. Dedicada a reconocer globalmente las imágenes en función de sus características narrativas; y Formativa. Se propuso determinar el tipo de aprendizaje que conlleva la representación fotográfica.

La primera fase fue indispensable, pues la descripción en detalle permitió no desvincular la imagen del contenido y del contexto para sobrepasar lo puramente visual y transmitir los posibles significados de las representaciones. Aunque parezca que solo evalúa el significado literal, al tratar de relacionarla con el tiempo y lugar como contexto histórico, se reconoce una significación ideológica que es la que se profundizó en la última fase del análisis. Las fases intermedias ayudaron a interpretar aspectos, técnicos, formales, simbólicos y contextuales para finalmente concluir en un acercamiento al modo en cómo educaron. Todas las fotografías aparecieron en medios en secciones relacionadas con el proceso de paz como: política, acuerdo de paz, poder, nación, democracia, justicia, justicia especial para la paz y posconflicto. Las 5 imágenes elegidas no hicieron parte de las que tuvieron mayor reiteración durante este momento histórico. Escogerlas hizo parte de la estrategia para identificar que lo que no se muestra también es presencia de la imagen y de esta visibilidad agente (Renaud, 1990), se desprende también, el aprendizaje obtenido por nosotros como ciudadanos. En otras palabras la profundización de estas últimas buscó interpretar su actuación sobre las representaciones vigentes y sobre los imaginarios alrededor del proceso de paz a partir de su asociación con imágenes altamente reconocidas y con hitos históricos dentro del proceso de paz que fueron, además de informados, comunicados y espectacularizados por los medios de comunicación.

\section{Investigación - Creación y experiencia estética}

En el marco de la investigación creación y tomando en cuenta los objetivos iniciales, los supuestos identificados y los resultados obtenidos del ejercicio teórico y analítico, se propuso un ejercicio creativo no convencional cuyo resultado invitara a tomar conciencia, a adoptar posturas críticas y cuestionadoras frente a lo que vemos. El proceso inició con un esquema semiótico con los 3 aspectos de la segundidad del signo peirceano -ícono, índice y símbolo(CP 2.243 y ss), que permitiera referir una manifestación concreta del signo, es decir, una 
actualización material. La apropiación que se hizo de este modelo se hxo sobre la base del nonágono semiótico (Guerri, 2014) y se explica a continuación: El ícono como las cualidades del objeto fotografía (imagen/mirada), el índice proporciona pistas para el interpretante (estrategias pedagógicas/didácticas/poder) y el símbolo, las interpretaciones de carácter simbólico en el marco normativo del proceso de paz que se espera confluyan durante la exposición de la obra resultante. La dinámica interna de interrelación entre estos tres aspectos y por ende entre los tres aspectos de la primeridad y los tres aspectos de la terceridad fue de gran importancia para el proceso creativo, pues potenció el universo creativo metafórico.

Tres aspectos descriptivos del signo fotografía como panóptico que sobresalieron fueron: medios de comunicación digitales, educación y domesticación. El primero, en alguna relación, es la percepción, específicamente el sentido de la vista. El segundo, por algo, es la acción específica que se origina con la fotografía. El tercero los condicionantes o normas que conllevan el para qué, para la domesticación de la población. Estos se complejizaron con los resultados arrojados por las matrices de análisis de las 5 fotografías descritas y en un proceso abductivo de observación profunda se propusieron diferentes cuestionamientos aleatorios.

El proceso realizado sobre las fotografías elegidas acerca del proceso de paz entre el Estado Colombiano y la guerrilla de las FARC por la fotógrafa Laura Vega tuvo como resultado la video instalación "Colección panóptico de la educación para la paz". Compuesta por 5 tomos impreso/digitales en edición de lujo para ser expuestos en atriles enclavados en la pared cuya característica principal es ser manos sólidas, blancas e inmóviles. Su primera exhibición se dio en un espacio universitario ante un grupo de académicos del área de las artes y el diseño, la filosofía de la imagen y la teoría de la fotografía; además de estudiantes de pregrado y público externo invitado

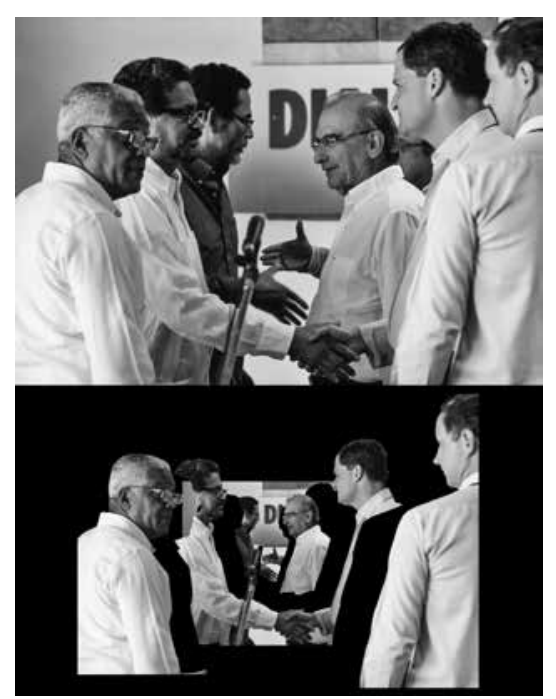

Figura 1. Captura digital de la imagen en pantalla y reinterpretación de la Imagen Fotográfica. 
Su puesta en escena contó con el conocimiento previo del público sobre el proceso de paz y las imágenes que lo acompañaron, por lo que se esperaba la recordación de cada uno de los hitos representados. La experiencia aspiraba a que las fotografías detonaran imaginarios colectivos como testimonio subjetivo de algún tipo de conocimiento adquirido de ese momento histórico (Figura 2).

\section{Notas sobre la video-instalación}

Cada uno de los componentes expuestos en la video instalación sustentó la necesidad de tomar conciencia y asumir una postura crítica que interpele a la imagen, no solamente por parte del fotógrafo creador de la obra, sino por cada uno de sus espectadores. En favor de lograrlo y sin desconocer la autonomía del interpretante se pretendió la siguiente lectura por separado de cada uno de los elementos:

Los medios de comunicación digitales se referencian en las manos que sostienen el libro/ pantalla. Hace alusión a la frase "estar al alcance de la mano", que quiere decir que es de fácil acceso, pero también al tacto debilitado, pasmado y sometido por el ocular-centrismo. La educación, encarna el imaginario del conocimiento centrado en la cultura letrada que se obtiene en los libros, ligado a la verdad y aceptado sin duda alguna. Es una convencionalidad que todos, o al menos la mayoría acepta sin dudar y que hoy en día se le adjudica a la inmensidad del contenido en red, ¿Es solo un cambio de soporte?

La domesticación, conclusión principal de lo obtenido con la educación impartida por las instituciones que ostentan el poder se da en la experiencia del espectador con la obra. El título de cada tomo se basó en títulos de autores reconocidos, metáfora de ideales, intereses, pasiones o preocupaciones que capturaran la atención. -Vol.I. Diplomacia tomando un café; Vol.II La globalización en un mundo en transformación; Vol.III Los límites del patriotismo; Vol.IV Hombres en tiempos de oscuridad; Vol.V Manifiesto para una democracia de la tierra-. El espectador ya no lo es más, ahora convertido en usuario, desea abrir cada libro. Explorar, escudriñar y agotar su sed de conocimiento, aún cuando la sed de imagen no se sacia nunca. Encuentra lo que busca, una pantalla que le revela las insistentes imágenes de la verdad oculta. El encuentro consigo mismo, con su imaginario del proceso de paz, se refleja como en un espejo... observa al tiempo que es observado. La imagen final es un panóptico desde el cual se autovigila.

La video instalación quiso invitar a la reflexión, hizo parte de los mecanismos alternativos para "educar la mirada". Estrategia no convencional que desde el arte (Cartagena, 2015), buscó mostrar a través de metáforas del cuerpo, del conocimiento y de la mirada manipulada, la evidencia, a veces obvia, de lo que nos sucede a diario frente a las pantallas.

Se permitió al público recorrer la video instalación libremente. En una primera apreciación de la experiencia se notó una postura de contemplación de la obra de arte en un intento del grupo de espectadores por comprender la esencia conceptual, aunque también, cuestionaron los diferentes tipos de edición y efectos asignados en cada imagen según el hito que identificaba. En un momento posterior se realizó una observación sustentada, en donde la autora puso en consideración pautas artísticas, aspectos técnicos de la obra, 
así como una síntesis del resultado del análisis realizado a cada fotografía sustraída de los medios para la instalación.

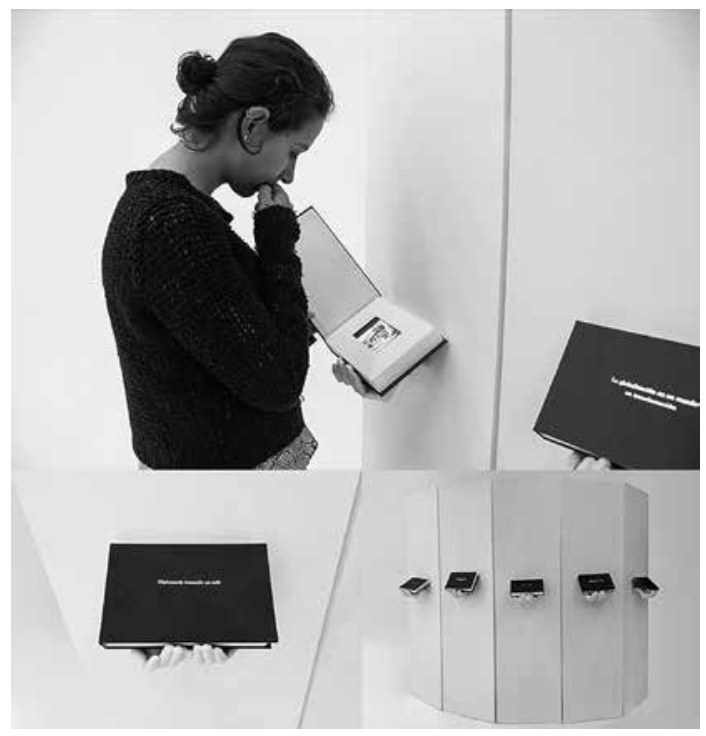

Figura 2. Fotografía durante la exposición. Oficina de Comunicación Utadeo y Archivo Personal Laura Vega.

\section{Comentarios finales}

Colombia un país atravesado por la violencia, plagado de soluciones acomodadas y sesgadas políticamente y por lo general sólo vigentes mientras dura el gobierno de turno, es nuestro país. Su transformación es responsabilidad de todos, cada uno desde lo que sabe, lo que piensa, lo que hace, debería trabajar por otro desarrollo posible, más local, más acorde con nuestra identidad. De tal forma, desde la formación particular, nos cuestionamos por la imagen fotográfica, sus alcances, sus posibilidades, pero también en lo que encubre.

Lo descubierto a través de la observación, el análisis semiótico y el proceso de creación sobre el inconcluso proceso de paz entre el gobierno Santos y las FARC, abre caminos de profundización sobre el poder de la imagen y su uso por parte de quienes detentan el poder no solo en este caso sino en otras muchas situaciones que terminan siendo veladas para dar paso a la siguiente noticia más espectacular que la anterior.

Definitivamente consideramos que el Estado promueve un sistema educativo con un ideal eurocéntrico de la educación, reflejo del mínimo saber que debe poseer una sociedad oprimida. Hay que controvertir el sistema educativo moderno y dar cabida a una "pedagogía 
de la imagen". Pero esta pedagogía no funciona automáticamente, tiene unos lineamientos que la hacen posible, el primero,

Poner en cuestión toda una tradición de los sistemas educativos modernos, en los que la imagen ha sido generalmente despreciada como una forma de representación inferior y menos legítima que la escritura. En segundo lugar, cuando hoy se trae la imagen a la transmisión, se la considera un reflejo transparente de realidades simples, una ilustración casi redundante de argumentos reflexivos vinculados a otras formas de expresión (que también, equívocamente, se creen transparentes y simples) (Dussel, 2006 p. 12).

Hablar de "educar la mirada" (Dussel, 2006) en la cultura visual de hoy despierta un interrogante: ¿Cómo es posible enseñar a mirar en un contexto en el que todos se asumen altamente calificados para ver, aunque las evidencias demuestren lo contrario? Es un reto enseñar a mirar en un mundo poblado y saturado de imágenes. Es preciso entonces, fomentar una pedagogía de la imagen con varios niveles de profundidad alejados de la idea de que esta es un simple recurso simple utilizable con didácticas instrumentales.

Entonces se reconoce que lo que vemos en una imagen no es realmente lo que nos es mostrado, supone una mayor profundidad comunicativa en la cual prima su capacidad discursiva en sí misma y su potencia subjetiva otorgada por el pensamiento fotográfico de su productor. A través de estos el espectador interactúa se somete o se rebela. De tal forma, informes y noticias aprovecharon las imágenes fotográficas y educaron para "un tipo de paz" provocando la sujeción a los intereses de un sistema dominante. Entre lo aprendido está la idea de gobierno mesiánico, la transparencia del proceso, la paz como un logro personal, la obligatoriedad del perdón, entre otros.

Los desarrollos tecnológicos nos ponen de cara a la pantalla y al exceso de información, juntos producen en el sujeto una falsa idea de sentirse unido, cercano e informado cuando finalmente lo que hay es una clara exposición de la intimidad y una falsa consciencia. La fórmula parece ser, a más información, más manipulación. Los medios nos muestran una realidad sugerida y la tecnología con su accesibilidad y la experiencia de usuario nos hace creer que somos libres de expresar nuestra individualidad, cercenando el pensamiento de usuario. Según Althusser "funcionan masivamente con la ideología como forma predominante pero utilizan secundariamente, y en situaciones límite, una represión muy atenuada, disimulada, es decir simbólica”. La fotografía materializa la idea cerrando el ciclo de la representación para dar cuenta de su función como aparato ideológico del Estado.

Mientras que no haya una "educación de la mirada" lo que pase ante nuestros ojos siempre será el punto de vista del poder hegemónico. Detenernos en la aprehensión de la imagen, supondrá tiempos y espacios diferente a los que la velocidad de los medios nos ha acostumbrado. Afinar la mirada y sospechar no sólo de este álgido tema que nos convoca en esta reflexión, sino de otros que ilustrados con imágenes fotográficas e insistentemente repetidos en formatos digitales, van armando lo que somos. Mecanismos alternativos, espacios cotidianos y acercamiento profundo a lo que somos como nación ayudará a fortalecer el espíritu y ampliar el espectro para por fin entender que la mayoría de la información no es comunicación, que el contenido de las imágenes fotográficas va más allá de las noticias 
que ilustran y que la manipulación simbólica está más presente que lo que lo que queremos reconocer.

El debate sobre el poder educador de la imagen está vigente. Y las preguntas sobre pedagogías, metodologías y didácticas esperan respuestas múltiples que respondan a la diversidad de medios a través de los cuales la fotografía opera y a las posibilidades de aprendizaje mediado por pantallas y dispositivos móviles en tiempos y espacios abstractos. Reconocer que la imagen enseña en contextos no tradicionales para el aprendizaje es urgente, es el primer paso para entender cómo se logra la manipulación invisible a la que nos vemos abocados. Promover un pensamiento fotográfico en nuestro país, pasar de ser simples espectadores a reconocer y entender las potencias de la imagen, que posibilite entender las versiones de la realidad nacional que desde el poder se manifiestan ante nuestros ojos, cuestionar, controvertir y subvertir esa realidad sesgada para preguntarnos ¿sumisión o resistencia?

\section{Bibliografía}

Agamben, G. (2011). ¿Qué es un dispositivo?. Sociológica (México), 26(73), 249-264.

Althusser, L. (1988). Ideología y aparatos ideológicos del Estado. Freud y Lacan. Buenos Aires: Nueva Visión.

Betancourt, M. X. (2014). De la identidad social a la representación visual, estrategias de intervención desde el diseño responsable. Kepes, 11(10).

Brea, J. L. (2005). Los estudios visuales: por una epistemología política de la visualidad. In Estudios visuales: la epistemología de la visualidad en la era de la globalización (pp. 5-14). Akal.

Cárdenas, J. D. (2013). Opinión pública y proceso de paz: actitudes e imaginarios de los bogotanos frente al proceso de paz de La Habana entre el gobierno colombiano y la guerrilla de las FARC. Ciudad Paz-ando, 6(1), 41-58.

Cartagena, M. F. (2015). Arte, educación y transformación social. Index, revista de arte contemporáneo, 44-61.

Cigüela Sola, J. \& Martínez Lucena, J. (2014). El imaginario social de la democracia en Black Mirror.

Colombia, Acuerdo de Paz. Recuperado de www.cancilleria.gov.co./cartilla abcdelacuerdo final2

Didi-Huberman, G. (2017). Lo que vemos, lo que nos mira. Manantial.

Dussel, E. (2011). Filosofía de la liberación. Fondo de cultura económica.

Dussel, E. (2016). Decolonialidad del poder con Enrique Dussel [Archivo de video] [Códigos Libres].Recuperado de https://www.youtube.com/watch?v=BBe1W63uLjM

Dussel, I. (2006). Educar la mirada: políticas y pedagogías de la imagen. Ediciones Manantial. Fontcuberta, J. (2016). La furia de las imágenes: Notas sobre la postfotografía. Barcelona: Galaxia Gutenberg.

Foucault, M. (2000). Vigilar y castigar: nacimiento de la prisión. Siglo XXI.

Freire, P. (1982). La educación como práctica de la libertad. Siglo XXI. 
Fundación Paz y Reconciliación. https://pares.com.co/2019/01/04/procesos-de-paz-en-co lombia/ Consultado el 10 de octubre de 2019.

Guerri, C. \& Acebal, M. (2014). Nonágono semiótico. Buenos Aires: Eudeba.

Imbert, G. y Beneyto, J. (coords.) (1986). Fotografía y libertad de información. El País.

Najafi, I.; Kamyar, M.; Kamyar, A. \& Tahmassebpour, M. (2017). Investigation of the correlation between trust and reputation in $\mathrm{B} 2 \mathrm{C}$ e-commerce using Alexa ranking. IEEE Access, 5, 12286-12292.

Ministerio de Tecnologías de la Información y las Comunicaciones (MinTIC) (2019). Plan Estratégico Institucional MinTIC 2019-2022. Bogotá, Colombia: MinTIC. Recuperado de https://n9.cl/dj2qv

Osorio Porras, Z. (2016). Personas ilustradas: la imagen de las personas en la iconografía escolar colombiana. CAB.

Pallasmaa, J. (2006). Los ojos de la piel (No. 159.93: 72). Gustavo Gili.

Peirce, C. S. (1960). Collected papers of charles sanders peirce (Vol. 2). Harvard University Press.

Pérez, A. U. P. (2011). Implicaciones epistemológicas de la fotografía y su influencia como dispositivo panóptico en la cultura digital. Filo de Palabra, (10).

Quijano, A. (2000). Colonialidad del poder, eurocentrismo y América Latina.

Ranking Alexa, top sites in Colombia, by country, amazon.com

Renaud, A. (1990). Videoculturas de fin de siglo.

Ribeiro, L. A. T. (1999). Manipulación en el fotoperiodismo: ética o estética. Revista Latina de comunicación social, 22(6).

Rincón, M. H. (2001). La pantalla. Notio, opus, taktike. Bogotá: Unibiblos.

Rossi, L. S. R. (2018). Agenciamientos en las sociedades de control. Cultura-Hombre-Sociedad, 28(1), 177-206.

Santos, J. M. (2019). La batalla por la paz. El largo camino para poner fin al conflicto con la guerrilla más antigua del mundo. Madrid: Planeta.

Vargas, J. Á. V. (1993). La verosimilitud. Revista de Filología y Lingüística de la Universidad de Costa Rica, 19(1), 7-16.

Walsh, C. (2003). Las geopolíticas del conocimiento y colonialidad del poder. Entrevista a Walter Mignolo. Polis. Revista Latinoamericana, (4).

Virilio, P. (1998). La máquina de la visión. Madrid, España: Cátedra.

Abstract: There is a need to reflect the "educational role" that photography plays in the
domestication of the population, while as a medium and device, offers manipulated read-
ings of reality in favour of dominant interests. To contribute to the discussion of the role
and meaning of photography today, the Colombian Peace Process is addressed as a trigger
for the following analysis. Thus, the beginning of the 21 st century settles the paradigm
of the Colombian "reality", throughout the photographs that circulate on the media rep-
resenting Colombians themselves and their image worldwide. The signing of the Peace
Agreement in 2016 marks the beginning of a new era "post -conflict" or "post -agreement". 
Several events where notable along the process: long meetings, encounters and confrontations, in addition to demonstrations, all captured by official and private photographers. Their posture and gaze, the instant of the shot and the edition afterwards, the ideology of the medium that spread it, among other things, are part of ways in which education as an ideological apparatus of the state expresses itself outside the walls of educational institutions. Now using technologies as instruments, giving a clear path to the reproduction of power, re-signifying and altering through codes that "reality" in which we are inscribed.

Keywords: Educating the gaze - Photographic image - Screens - Panopticon - Education and power - Media - Representation.

Resumo: É premente a necessidade de refletir sobre o papel "educativo" que a fotografia cumpre na domesticação da população enquanto meio e dispositivo que orienta leituras manipuladas da realidade a favor dos interesses dominantes. O processo de paz é o gatilho para que as análises apresentadas neste texto contribuam para a discussão sobre o papel e o significado da fotografia na atualidade. Este tema articula a "realidade" colombiana do início do século XXI como um contexto com a forma como é representada perante os próprios colombianos e perante o mundo através das fotografias que circulam nos meios de comunicação. A assinatura do Acordo de Paz no final de 2016 dá início a uma "nova era" para alguns "pós-conflito", para outros "pós-acordo". Vários marcos marcam esse processo: longas reuniões, encontros e confrontos, além de manifestações, foram captados por fotógrafos oficiais e particulares. Sua postura, seu olhar, na hora de tomá-la, sua edição, a ideologia do meio que a disseminou, entre outras coisas, fazem parte das formas pelas quais a educação como aparelho ideológico do Estado se expressa fora do As paredes das instituições de ensino, hoje em uso das tecnologias que se instrumentalizam, dão rédea solta à reprodução do poder, ressignificando e distorcendo por meio de códigos essa "realidade" em que estamos inscritos.

Palavras chave: Educar o olhar - Imagem fotográfica - Telas - Panóptico - Educação e poder - Mídia - Representação.

[Las traducciones de los abstracts fueron supervisadas por el autor de cada artículo] 